\title{
Ways of Expressing Causation in Modern English
}

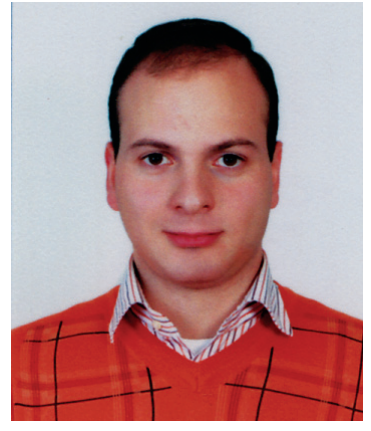

Robert Khachatryan

Sentences are linguistic means of describing events

$\checkmark$ and actions that occur in the world. Events and actions are bound by various relations. For example, an action may cause another action to happen or it may set the stage for another event to take place. Causation among actions has been of great interest to philosophers of language, partially because "most languages in the world have a range of lexical expressions specifically designed for communicating causal relations (Stukker et al 2008: 1297).

Causation reflects human cognition of cause-effect relationships, which is shared by all speakers of all languages. Therefore, all natural languages offer multiple ways of expressing causation, but they differ in the means. In some languages, there are morphological devices that change verbs into their causative forms or adjectives into verbs of "becoming". Other languages employ periphrasis, with idiomatic expressions or auxiliary verbs. All languages also have lexical causative forms.

Causation is grammaticalized and lexicalized differently in different languages although the core of causative meaning, the cause-effect relationship, is a cognitive and experiential universal. Causation is defined as "some relation of determination between two events, with a prior event resulting in or giving rise to a subsequent event" (Frawley 1992: 158). Similar view is held by L. Talmy "causatives involve relation of a precipitating event and a resulting event (Talmy 1985: 130). As L. Talmy continues "causativity refers to whether an event is conceived either as occurring by itself or resulting from another event, where this latter event is either initiated by an agent or not, and such an agent is either volitional or not" (Talmy 1985: 132). Causativity is the lexicalization of causation.

The aim of this article is to elaborate on ways of expressing causation in Modern English. The phenomenon of causation can be expressed in natural language by a wide variety of linguistic constructions. All these constructions express different aspects of the same situation - the causative situation. A causative situation is generally defined as "a relation between two events: the causing event and the caused event occurring in temporal succession and causally dependent on each other" (Talmy 2000: 478-9). Shibatani also considers "the causative situation to be a relation between two events: the causing event and the caused event. The caused event would not have taken place (at that particular time) if the causing event had not taken place" (Shibatani 1976: 28). This basic causative situation underlies all linguistic expressions of the phenomenon.

Languages tend to have a construction specifically designed to express causative relationships in which the causing event is not elaborated beyond the notion of cause. 
The causative construction is "a linguistic expression which denotes a complex situation consisting of two component events: the causing event, in which the causer does or initiates something, and the caused event, in which the causee carries out an action, or undergoes a change of condition or state as a result of the causer's action" (Comrie 1989: 165-166). The causative construction is one of the most theoretically significant aspects of English grammar and an understanding of causatives is fundamental to an understanding of clause structure as a whole (Shibatani 1976: 1-2, Song 1996: 12, Dixon 2000: 30-31). Consequently, analyses of the causative have had a major influence on many foundational aspects of syntactic theory and the morphology-syntax interface.

A common approach to causatives is to consider them to be derived by reduction, either of clauses or predicates. Comrie, for example, states that causative constructions result from "the compression of an underlying complex structure with embedding into a derived structure simple sentence" (Comrie 1976: 303). Causative is a "transitive construction, related to a second, simpler, transitive or intransitive construction from which it differs by the additional presence of an agent noun-phrase perceived as the direct instigator of the action expressed in the simpler construction. Causatives in this sense are susceptible of a variety of surface syntactic expressions in English" (Trask 1993: 38). In other words, a causative is a verb or verbal construction,

Verbs are called causative "when they are transitive and entail a change in the condition or location of the direct object brought about by the action of the subject": e.g. He broke the window. He flattened the pipe. He killed the spider. (Dillon 1977:124). Causative verbs are "derivable form one-place intransitive constructions by means of a causative operation, which has the effect of embedding a one-place nucleus into a matrix sentence with an abstract causative verb, and combining the predicate element of the embedded clause with that of a higher clause" (Olszewska 1985:253).

English provides several different ways of expressing causal relations. Thus, English has a threefold causative system of grammaticalization (Comrie 1989:167):

- a series of simple verbal propositions, i.e. a sequence of separate, causally related events (action chain): e.g. John bought a knife because he needed it;

- a complex verbal proposition, i.e. a complex event: e.g. John made us suffer;

- one simple proposition, usually the "effect", i.e. a single event: e.g. The bottle broke.

Cause and effect can be lexicalised with two different verbal elements or conflated into one verb (Kemmer 1994: 118). Degree of fusion leads to different types of causatives. In English, the idea of causativity is mainly expressed (Katamba 1993:213):

- lexically, by underived lexicalized forms like to drop (cause to fall), to kill (cause to die), teach (cause to learn);

- morphologically, typically by inflectional morphemes and by derivational affixation as in to widen (make wide), to shorten (cause to become short);

- syntactically, by separate words in phrases and clauses that contain the concept of make or cause.

There are a number of other structures that may also express the notion of causativity in English, namely subordinating conjunctions and prepositional phrases: 
- causal conjunctions or causal connectives (because, since, so that, hence, thereby, if, etc.);

- causal prepositional phrases (because of, due to, thanks to, owed to, by dint of, etc.).

Causal conjunctions, including conjunctive adverbs, and causal prepositions are similar to one another in the components of causal meaning. In all cases, the main clause expresses the result and the subordinate clause expresses the cause. Causal subordinating conjunctions typically introduce a clause that can be best characterized as expressing a reason: e.g. There's a hole in the screen door because I tripped over the cat. I made it on time because the traffic lights changed just in time. (Dancygier and Sweetser 2000:25)

\section{Analytic causatives.}

One common means of describing causal relationship is analytic causatives, in which the two underlying events are condensed into one simple clause. Considering morphological features, an analytic causative is described as "a two-verb structure that expresses a predicate of causation and a predicate of effect" (Kemmer and Verhagen 1994: 128), the causal predicate being termed in many languages "auxiliary", indicating that it has no full verbal status. Accordingly, only one of the two verbs involved in the construction has all the formal trappings of a normal verbal element, i.e. occurs with tense/aspect marking; the other verb is an infinitive.

When Winifred married Dartie, I made him bring every penny into settlement - lucky thing, too - they'd ha' had nothing by this time! (Galsworthy, The Man of Property)

The image raised caused her to take pity upon herself as one who was ill-used. (Hardy, Tess of the d'Urbervilles)

This means of expressing causation is the use of a verb that includes the notion of cause without specification of a particular result, as in the verbs to make, cause, let, get etc. (Comrie 1989, Fodor 1970, Levin and Rappaport Hovav 1994, Shibatani 1976) Such verbs are often referred to as periphrastic causatives (also called auxiliary or overt causatives), and they express causal relationships with two or more predicate terms, one associated with the cause and the other with result. (Kemmer and Verhagen 1994; Wierzbicka 1998) Early work on periphrastic causatives assumed that the class of periphrastic causative verbs was limited to a small, grammatically determined set of words, the most common being to cause, make, get, have and let. (Ammon 1980, Shibatani 1976) However, more recent work has suggested that the class might be much larger, including such verbs as to allow, convince, force, permit, persuade, etc. (Talmy 1988)

An analytic causative construction is a "construction that overtly encodes causing and resulting events separately such that the morphosyntax encoding the effected event is in some way dependent on the morphosyntax encoding the causing event; furthermore, the causing event is encoded by a general verb expressing primarily causation, and hence its precise nature is left unspecified". (Comrie 1989:167; Kemmer and Verhagen 
1994:117) Thus, periphrastic construction is used when a speaker views the underlying causing event as causally dependent on some action of the agent of the causing event, no matter what this action is. The causing event itself is thus not overtly specified, all that remains is the pure notion of cause expressed by a causal predicate. (Degand 1994:111) In analytic causatives, the subject of the cause event becomes the object of the causative verb, regardless whether the caused event is transitive or intransitive.

Therefore, analytic causatives are bi-clausal constructions or two-clause expressions that encode the notions of cause in the main verb and the notion of the result in the embedded verb. (Kozinsky and Polinsky 1993) Periphrastic causative verbs are defined by both syntactic and semantic criteria. Syntactically, periphrastic causative verbs take clausal complements. Semantically, periphrastic causative verbs entail the occurrence of a result or the change of state or location. (Shibatani 1976)

\section{Lexical causatives.}

Another common and productive ways of expressing causal relations is with lexical causatives (also called covert or underived causatives), i.e. verbs that are discernibly semantically causative, but are not formally analyzable into two morphemes. Such verbs involve maximal conceptual closeness of the causal and effected predicate. The causal predicate is not only semantically but also morphologically dependent on the effected predicate; and the causative structure is more obviously monoclausal. Thus, lexical causatives are pairs of lexical items that have a causal relation between them. Levin and Rappaport propose that the English causative alternation takes place in the lexicon, i.e. a language simply uses a different lexical item to indicate a causative form. (Levin and Rappaport Hovav 1995) For example, the causative of English to rise is to raise and the causative of to eat is to feed. However, there is no regularity in such causative constructions. (Singh 1992) English allows a notable freedom in verb valency, resulting in verbs like to break, burn or awake, which may be causative or not (he burns it = he causes it to burn). Causativeness is therefore zero-marked in many English verbs.

A causal event in lexical causatives is possible to describe within a single clause. Lexical causatives are not usually the constructions open for lexical filling. They are, as usual, the words expressing cause to action, "the members of suppletive and correlative stem oppositions and they correlate with other words deprived of causative meaning, the so-called anticausatives". (Haspelmath 1993) In other words, some transitive verbs have fairly clear non-causative counterparts, which are considered lexical causatives: to kill to die, to feed - to eat, to teach - to learn, to rise - to raise, to lie - to lay, to sit - to set. The former members of these suppletive oppositions: to kill, to feed, etc express the states caused by force. The latter members to die, to eat express the states, which are the results of developing events.

And now this morning thou shalt watch that flame again, for I will give thee one inch more of candle, and when the pin drops, will put this thine own pistol to thy head, and kill thee with as little thought as I would kill a stoat or other vermin. (Falkner, Moonfleet) 
Later, he noted with satisfaction that the sounds of feet had died away. (Zelazny, Jack of Shadows)

Causative verbs can differ from the corresponding non-causatives by varying the stem vowel, e.g. to fall ? to fell, to lie? to lay, to rise? to raise, etc.

Halting his tall, lank figure before her, he raised a finger, and levelled it at her bosom, as though bringing an indictment against her beauty... (Galsworthy, The Man of Property)

An enormous wave of pinkish-ochre sand rose up in front of the impact site like a great wall. (Cooper, The Runaway Asteroid)

In this case, the main condition of expressing causation is to make the verb transitive. Here causation and transitiveness become equal in their grammatical meaning; nevertheless, causativity is special kind of transitiveness. If the usage of common transitive verbs without object is possible grammatically, then causativity verbs cannot be used without object. Moreover, "if the action expressed by the transitive verb simply passes on to the object, then the action expressed by the causative verb not only passes on to the object, but also additionally causes it to act or turn into a new state". (Zhirmunskij 1963: 3-4)

He put his hand on my arm and walked me away from the cars.

Lexical causatives differ most significantly from periphrastic causatives with respect to the notion of direct causation. Whereas periphrastic causatives can be applied to causation that is either direct or indirect, lexical causatives are restricted to direct causation (Levin and Rappaport Hovav 1994; Shibatani 1976; Wolff 2003). To illustrate this difference, consider the following examples: Sara opened the door (lexical causative) and Sara caused the door to open (periphrastic causative)

\section{Morphological causatives.}

In the case of morphological causatives, the causal and effected predicates are expressed in one word composed of two morphemes, one indicating the causal predicate and the other the effected predicate. In languages with morphological causatives, the causal predicate is not only semantically but also morphologically dependent on the effected predicate; and the causative structure is more obviously monoclausal. (Kuroda 1992)

In Modern English, the morphological causative is the most common way of expressing causative relations. Typically, morphological causative is formed by regular and productive way, mostly by special affixation or inner flexion (Comrie 1989: 167168). In English, the most common causative affixes are:

- suffix -ize: to modernize (to cause to become modern), to familiarize (to cause to become familiar), to legalize (to cause to become legal), to spiritualize (to cause to become spiritual), etc. 
It had taken considerable time for him to familiarize himself with the areas involved, obtain the necessary credentials, and learn the teaching routine. (Zelazny, Jack of Shadows)

She spiritualizes them, and one feels that they are of the same flesh and blood as one's self. (Wilde, The Picture of Dorian Gray)

- suffix -en: to strengthen (to cause to become strong), to lengthen (to cause to become long), to widen (to cause to become wide), to blacken (to cause to become black), etc.

To strengthen an impression so desirable and useful, he followed up the blow by acquainting him, in some detail, with the magnitude and extent of his operations; blending truth and fiction together, as best served his purpose; and bringing both to bear, with so much art, that Mr. Bolter's respect visibly increased, and became tempered, at the same time, with a degree of wholesome fear, which it was highly desirable to awaken. (Dickens, Oliver Twist)

We moistened the parched lips, and the patient quickly revived. (Stoker, Dracula)

- suffix -(i)fy: to purify (to cause to become pure), to clarify (to cause to become clear), to simplify (to cause to become simple), etc.

Such will, of course, immensely simplifies our labor, and the sooner the matter is attended to, the better. (Stoker, Dracula)

The whiskey had both soothed and clarified the restless things in his mind. (Fitzgerald, The Beautiful and Damned)

- prefix en-: to enlarge (to cause to become large), to enslave (to cause to become a slave), to enrich (to cause to become rich), etc.

Having now fixed my habitation, I found it absolutely necessary to provide a place to make a fire in, and fuel to burn: and what I did for that, and also how I enlarged_my cave, and what conveniences I made, I shall give a full account of in its place. (Defoe, Robinson Crusoe)

There were many private houses, which were enriched by travel; but his connection with the best families was as yet small. (Dreiser, The Financier)

- prefix em-: to embolden (to make somebody feel braver or more confident), to embellish (to make something more beautiful), to embitter (to make somebody feel angry or disappointed about something), etc. 
Wonderful civility this! It emboldened me to ask a question. (Bronte, Ch. Jane Eyre)

He was embittered by the conviction that all this desolation had been brought about by the accident of her being a d'Urberville. (Hardy, Tess of the d'Urbervilles)

It is of importance to make special comment on the specific nature of suffix-ize that forms verbs from nominal and adjectival roots and often gives the lexemes causative meaning. The semantic function of verbs can be demonstrated in the following way $\mathrm{X}+$ ize $=$ make $\mathrm{X}$. Here $\mathrm{X}$ is the stem of the adjective or noun, and "make X" - the meaning that the verb acquires: e.g. to modernize = to make modern, to localize = to make local, to popularize $=$ make popular, etc.

However, the conditional character of this model is revealed in some transitive but not causative verbs. For example, the verb to criticize cannot be presented as to make critic or even to make critical. The conditional character becomes evident if we reveal such verbs as to lionize = to treat somebody as a famous or important person; to agonize = to spend a long time thinking or worrying about a difficult situation and others, which are not causative. Analyzing this suffix, which is capable to form causative verbs, we see that causative meaning, though the main, is not however, the only one.

Thus, while all of the above-mentioned structures can be used to describe causal events, the constructions are not fully interchangeable. The ways in which various causal expressions might differ in meaning have been most fully explored in the case of lexical and periphrastic causatives. Most typically, the causative constructions show affinities to one-clause structure. Lexical causatives are single-clause expressions that encode the notions of cause and result. By hypothesis, these two notions are encoded within a single verb such as to melt, break, or kill. Periphrastic causatives are bi-clausal or two-clause expressions that encode the notions of cause in the main verb and the notion of the result in the embedded verb.

To conclude, we should state that one of the major syntactic differences between non-causative and causative constructions is the increased valency of the latter. A more interesting phenomenon is that the increased argument usually takes either a relation of direct object or a relation of indirect object. Thus, a causative may undergo valency expansion, i.e. undergo valency-increasing operation, which adds an element to the semantic and syntactic grids of the construction. In case the original verb is intransitive, then the causative construction is transitive: to lie ? to make (somebody) lie. In case the original verb is transitive, the causative construction is ditransitive: to eat (something) ? to make (somebody) eat (something). The valency of the verb increases by one with every level of causativization. The valency of an intransitive verb is one. Direct causation adds a causer and the valency becomes two. Indirect causation adds another causer and the valency of the indirect causative of an intransitive verb goes up to three. 


\section{References:}

1. Ammon, M. S. (1980) Development in the Linguistic Expression of Causal Relations: Comprehension of Features of Lexical and Periphrastic Causatives. $\mathrm{PhD}$ dissertation. Berkeley: University of California.

2. Comrie, B. (1976) The syntax of Causative Constructions. Cross-language Similarities and Divergences. / Shibatani, M. (ed).

3. Comrie, B. (1989) Language Universals and Linguistic Typology. 2-nd edition. Chicago: The University of Chicago Press.

4. Dancygier, B.; Sweetser, E. (2000) Constructions with if, since, and because: Causality, epistemic stance and clause order. // Cause, Condition, Contrast: Cognitive and Discourse Perspectives. / E. Couper-Kuhlen; B. Kortmann (eds). New York: Mouton de Gruvter.

5. Degand, L. (1994) Towards an account of causation in a multilingual text generation system. // Proceedings of the Seventh International Workshop on Natural Language Generation. Las Cruces, New Mexico, USA: New Mexico State University, Association for Computational Linguistics.

6. Dillon, G.L. (1977) Introduction to Contemporary Linguistic Semantics. New Jersey: Prentice-Hall.

7. Dixon, R.M.W. (2000) A Typology of causatives: form, syntax and meaning // Changing Valency: Case Studies in Transitivity. / Dixon R.M.W. and Aikhenvald, Al.Y. (eds). Cambridge: Cambridge University Press.

8. Fodor, J. A. (1974) Three Reasons for Not Deriving 'Kill' from 'Cause to Die'. // Linguistic Inquiry, N1.

9. Frawley, W. (1992) Linguistic Semantics. Hillsdale: Lawrence Erlbaum Associates.

10. Haspelmath, M. (1993) More on the typology of inchoative/causative verb alternations // Causatives and Transitivity. / Comrie, B. and Polinsky, M. (eds.) Amsterdam: John Benjamins.

11. Katamba, F. (1993) Morphology. Great Britain: Macmillan Press LTD.

12. Kemmer, S.; Verhagen A. (1994) The Grammar of Causatives and the Conceptual Structure of Events // Cognitive Linguistics. Vol. 5(2).

13. Kozinsky, Is.;Polinsky, M. (1993) Causee and patient in the causative of transitive: Coding conflict or doubling of grammatical relations? // Causatives and Transitivity. / Ed. by Bernard Comrie and Maria Polinsky. Amsterdam: Benjamins.

14. Kuroda, S. (1992) The Lexical and Productive Causatives in Japanese (An examination of the theory of the paradigmatic structure). San Diego: University of California.

15. Levin, B.; Rappaport Hovav, M. (1994) A Preliminary analysis of causative verbs in English // The Acquisition of the Lexicon. / Gleitman, L.; Landau, B. (eds.). MIT Press, Cambridge MA: Lingua.

16. Levin, B.; Rappaport Hovav, M. (1995) Unaccusativity: At the Syntax-Lexical Semantics Interface. Cambridge: The MIT Press, MA.

17. Olszewska, T. (1985) Causative Constructions in English and Polish. A Contrastive Study // Papers from the 6th International Conference on Historical Linguistics. / 
Fisiak, J. (ed.). Amsterdam/Poznan: John Benjamins/Adam Mickiewicz University.

18. Shibatani, M. (1976) The Grammar of Causative Constructions: A Conspectus // Syntax and Semantics. The Grammar of Causative Constructions. / Ed. by M. Shibatani. New York, San Francisco, London: Academic Press. Vol. 6.

19. Singh, M. (1992) An Event-based Analysis of Causatives // CLS: proceedings from the meeting of the Chicago Linguistic Society. 28.

20. Song, J.J. (1996) Causatives and Causation: A Universal-Typological Perspective. London and New York: Addison Wesley Longman.

21. Stukker, N.; Sanders, T.; Verhagen A. (2008) Causality in Verbs and in Discourse Connectives: Converging evidence of cross-level parallels // Journal of Pragmatics. $\mathrm{N} 40$.

22. Talmy, L. (1985) Lexicalization patterns: semantic structure in lexical forms // Language Typology and Syntactic Description: Grammatical Categories and the Lexicon. / Shopen, T. (ed.). Cambridge:Cambridge University Press, MA.

23. Talmy, L. (1988) Force Dynamics in Language and Cognition // Cognitive Science. N 12/1.

24. Talmy, L. (2000) Toward a Cognitive Semantics: concept structuring systems. Cambridge, MA/London: MIT Press. Vol. 1.

25. Trask, R.L. (1993) A Dictionary of Grammatical Terms in Linguistics. London and New York. N: Routledge.

26. Wierzbicka, A. (1998) The semantics of English causative constructions in a universal-typological perspective // The New Psychology of Language. Cognitive and Functional Approaches to Language Structure. / Tomasello, M. (ed.). NJ/London: Lawrence Erlbaum Associates Publishers.

27. Wolff, P. (2003) Direct causation in the linguistic coding and individuation of causal Events // Cognition 88.

28. Zhirmunskiy, V.M. (1963) Analiticheskiye konstrukcii. // Analiticheskije konstrukcii v jazukax razlichnux tipov. Leningrad: Institut Jazukoznaniya AN SSSR.

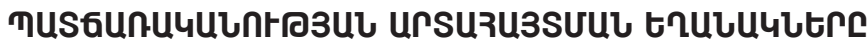 dUUUนU4Uदhs UఒqLtetuntU}

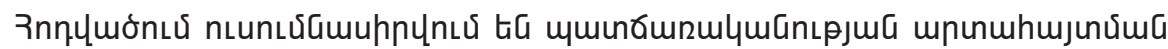

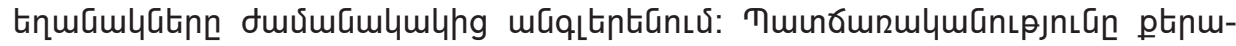

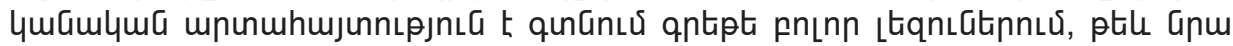

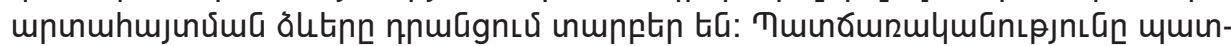

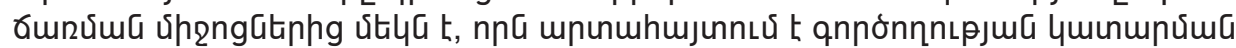

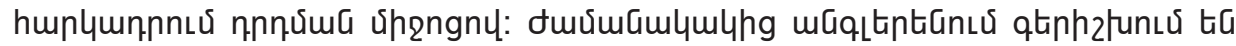

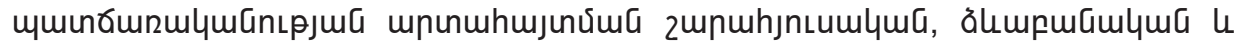
punmsha trnuGulatinn: 